Original scientific paper

\title{
DEVELOPMENT OF PASTERIZATION MODES FOR HIGH-SUGAR CANS IN CONTINUOUS ACTING PASTEURIZERS
}

\author{
Galina P. Pokudina*, Marina V. Trishkaneva, Raisa A. Volkova \\ Russian Research Institute of Canning Technology - Branch of V. M. Gorbatov's Federal Research Center \\ for Food Systems of RAS, Vidnoe, Moscow region, Russia
}

\section{KEY WORDS:}

continuous-acting pasteurizer (CAP), pasteurization modes, high-sugar products, packing temperature, required and actual lethality

\begin{abstract}
High-sugar canned fruits, such as jam, marmalade, confiture, are characterized by a high content of soluble dry solids and high acidity, which allows to apply to them pasteurization processes as heat treatment. In comparison with sterilization processes, heat treatment of hermetically sealed canned food during pasteurization is implemented at temperatures less than $100{ }^{\circ} \mathrm{C}$.

The article presents the results of the development of scientifically-based pasteurization modes for high-sugar canned food for industrial continuous-acting pasteurizers (CAP - continuous-acting pasteurizers) of open type with a temperature in the heating area less than $100{ }^{\circ} \mathrm{C}$. For today, such pasteurizers are widely spread due to the simplicity of their design, high productivity, with the option to reduce consumption of water, steam, electricity and to use it for the various types of packaging. So, the actual task of this article is the establishment of canned fruit pasteurization modes for such pasteurizers.

The development of pasteurization modes for high-sugar canned food using strawberry jam as a sample was carried out in the experimental equipment simulating the operation of a continuous-acting pasteurizer. The studies were implemented to confirm that the developed modes of heat treatment in the CAP as a matter of fact provide industrial sterility of the produced high-sugar canned food. Optimal pasteurization modes have the following parameters: heat treatment in an autoclave sterilizer at a heating temperature of the heating medium $97{ }^{\circ} \mathrm{C}$ and stage-by-stage cooling of the products with water at temperatures $70{ }^{\circ} \mathrm{C}, 50{ }^{\circ} \mathrm{C}$ and $30{ }^{\circ} \mathrm{C}$.
\end{abstract}

\section{Introduction}

The pasteurization process is preferable in comparison with the sterilization process in the subsequent manufacture of canned food for a range of products made of processed fruit. These products include the group of high acidic products with $\mathrm{pH}$ less than 4.2 and high-sugar canned food with a content of soluble dry solids within the range from 57 to $72 \%$, such as marmalade, jam, confiture and etc. [1]. High-sugar canned food is obtained by boiling of fruits and berries with sugar till the desired concentration of soluble dry solids (sugars). Such canned food is also characterized by the low content of active water $\alpha_{w}-$ less than 0.75. Canned food with a low value of $a_{w}$ (less than 0.85) are susceptible for spoiling mainly due to development of fungi and yeast in them, but the bacteria, do not develop when $a_{w}$ in the products is less than $0.85[2,3]$.

Thus the high concentration of sugars and organic acids in combination with the low content of active water in high-sugar canned fruit lead to destruction of yeast, fungi and vegetative forms of bacteria during heat treatment with temperatures below $100{ }^{\circ} \mathrm{C}$, which is typical for the processes of the canned food pasteurization.

Thermal pasteurization for food preservation is based on the concept of lethal effect of heat treatment on microorganisms (heating) $[4,5]$. Choosing the parameters of pasteurization modes - temperature and duration of products heating in autoclaves and pasteurizers, first of all the fact matters that the heat treatment mode provides industrial sterility of the produced canned food. In industrial-sterile canned food the microbiological stability and safety of the product are preserved throughout the shelf life defined for it. Canned food, heated at the temperature below $100{ }^{\circ} \mathrm{C}$, conforms to the requirements of industrial sterility in case if the actual lethality of the heat treatment process $A_{\text {fact }}$ is equal or slightly exceeds the value of the required lethality $A_{T}^{Z}: A_{\text {fact }} \geqslant A_{T}^{Z}[6,7,8]$.
The required lethality of heat treatment for canned food is referred to normative value equal to duration of heating in the least heated point of the product with the base temperature, which ensures the destruction of vegetative forms and spores of microorganisms, that cause the spoilage of the product $[6,9,10,11]$. Meanwhile choosing the new pasteurization modes it is necessary to take into account their impact on organoleptic parameters and nutritional value of canned products. The developed mode must guarantee the absence of the most heat-resistant microorganisms in the canned food, that can cause the spoilage of the product during storage, and also provide the organoleptic properties of the product [12].

The choice of the optimal pasteurization mode also depends on the type of packaging of the finished product, the design features of the pasteurizers used (immersive, steaming, irrigational), as well as the type and method of supplying a of the thermal agent (steam, water, water streams) to heat the canned products in the pasteurization zone.

Continuous-acting pasteurizers (CAP) of immersive and irrigational type are usually used for pasteurization of high-sugar products, packaged in glass jars or in heat-resistant polymer packaging $[13,14]$. In the industrial version this pasteurizer is a closed chamber with moving mesh transporter belt inside. The chamber consists of several zones: hot water pasteurization zone (heating zone) and 1-3 cooling zones. The cooling process is carried out by water or combined air and water method. In this case there are two types of cooling zones: air cooling zones and water cooling zones. The product remains in continuous motion during the entire pasteurization cycle in the CAP. The loading and the unloading processes are mechanized; the temperatures of the heating and cooling zones are set in accordance with the selected pasteurization mode. The temperature is maintained and recorded automatically, which ensures uniformity of the temperature area in the CAP zones $[15,16,17]$. 
The pasteurization of the canned food with using CAP has a range of advantages:

$\square$ no time intervals between packing and pasteurization of the canned food;

$\square$ decreased duration of the pasteurization process;

$\square$ reduced labor costs due to complete mechanization and automation of loading and unloading of canned food;

$\square$ reduced consumption of water, steam and electricity per unit of production;

$\square$ option to produce many types of canned food.

Thus the aim of the research is development of heat treatment mode for the high-sugar products (marmalade, jam, confiture, berries pureed with sugar, etc.), providing industrial sterility of the produced cans for continuous-acting pasteurizers with temperature below $100{ }^{\circ} \mathrm{C}$ without backpressure.

\section{Materials and methods}

The following equipment, materials and methods were used to perform the work:

$\square$ temperature recorder with automatic data processing (calculation of the actual lethality according to Bigelow) of brand «Ellab» CTF 9008 (Denmark) with a set of thermocouples for measuring of the temperature from 100 to $350^{\circ} \mathrm{C}$ with an accuracy of $0.1^{\circ} \mathrm{C}$. It was used to measure the temperature of the heating area in the autoclave and the temperature at the least heated point of the product;

$\square$ laboratory electric vertical autoclave VEE-2-1-0.08-0.3-3 UHL (Russia) with automatic setting of heat treatment modes, with working pressure- $3 \mathrm{MPa}$ and temperature of the heating area $135^{\circ} \mathrm{C}$. The autoclave simulates the heating zone of a continuous pasteurizer, in the experiment it was used without backpressure;

$\square$ three WCH-12 high-temperature circulation thermostats (Korea) with constant maintenance of water temperature $70{ }^{\circ} \mathrm{C}, 50^{\circ} \mathrm{C}$ and $30{ }^{\circ} \mathrm{C}$ (the simulation of pasteurizer cooling zones).

$\square$ strawberry marmalade with the content of soluble solids- $68 \%$, manufactured according to the normative docu- ment ${ }^{1}$, packaged in glass jars ${ }^{2}$ with screw lids, the diameter of the neck $68 \mathrm{~mm}$ and $350 \mathrm{~cm}^{3}$ volume (Jar 1) and the diameter of the jar neck is $82 \mathrm{~mm}$ and the volume is $650 \mathrm{~cm}^{3}$ (Jar 2), the temperature of the canned food packing before its immersion in an autoclave at $70{ }^{\circ} \mathrm{C}$.

$\square$ device «Citronics», Swiss, for measuring of $a_{w}$

sample test-culture of fungi-strains of Penicillium glaucum fungi spores

$\square$ agarised nutrient medium DG 18 with dichlorane and glycerin according to ISO16000-17:20083.

There was assembled the experimental stand for development of pasteurization modes, on this stand the simulation of the operation of a continuous immersive pasteurizer was carried out. Initially the canned strawberry marmalade was heated up to a temperature inside the product at $70{ }^{\circ} \mathrm{C}$ and immersed in the experimental vertical autoclave stand. The product in the autoclave was carried out heated up at temperatures of the heating area: $97^{\circ} \mathrm{C}, 95^{\circ} \mathrm{C}, 90^{\circ} \mathrm{C}$ (simulation of the CAP heating zone). Cooling was carried out in 3 thermostats with maintaining the temperature of the cooling area, respectively, $70{ }^{\circ} \mathrm{C}, 50^{\circ} \mathrm{C}$ and $30^{\circ} \mathrm{C}$ (cooling zone of the pasteurizer). The heating and cooling medium was water. Temperature of the canned food, heating and cooling medium was measured by the temperature recorder «Ellab». The schematic drawing of the experimental stand is shown in Figure 1.

\section{Results and discussion}

The required lethality for strawberry marmalade pasteurization modes with a $\mathrm{pH}$ value $=4,2^{4}$ (in foreign practice a control $\mathrm{pH}$ value $=4.6$ is used in accordance with document ${ }^{4}$ ) is selected from the conditions that ensure the death of mold spores of Penicillium glaucum, and is equal to $A_{T=80^{\circ} \mathrm{C}}^{Z=10^{\circ} \mathrm{C}}=40 \div 80$ conditional minutes.

\footnotetext{
${ }^{1}$ GOST 34113-2017 Gams. General specifications

2 GOST 5717.2-2003 Glass jars for canned food. Basic parameters and dimensions

${ }^{3}$ ISO 16000-17-2008 Indoor air - Part 17: Detection and enumeration of moulds - Culture-based method

${ }^{4}$ CAC/RCP 23-1979 (Rev.2-1993) «Recommended international code of
} hygienic practice for low and acidified low acid canned foods».

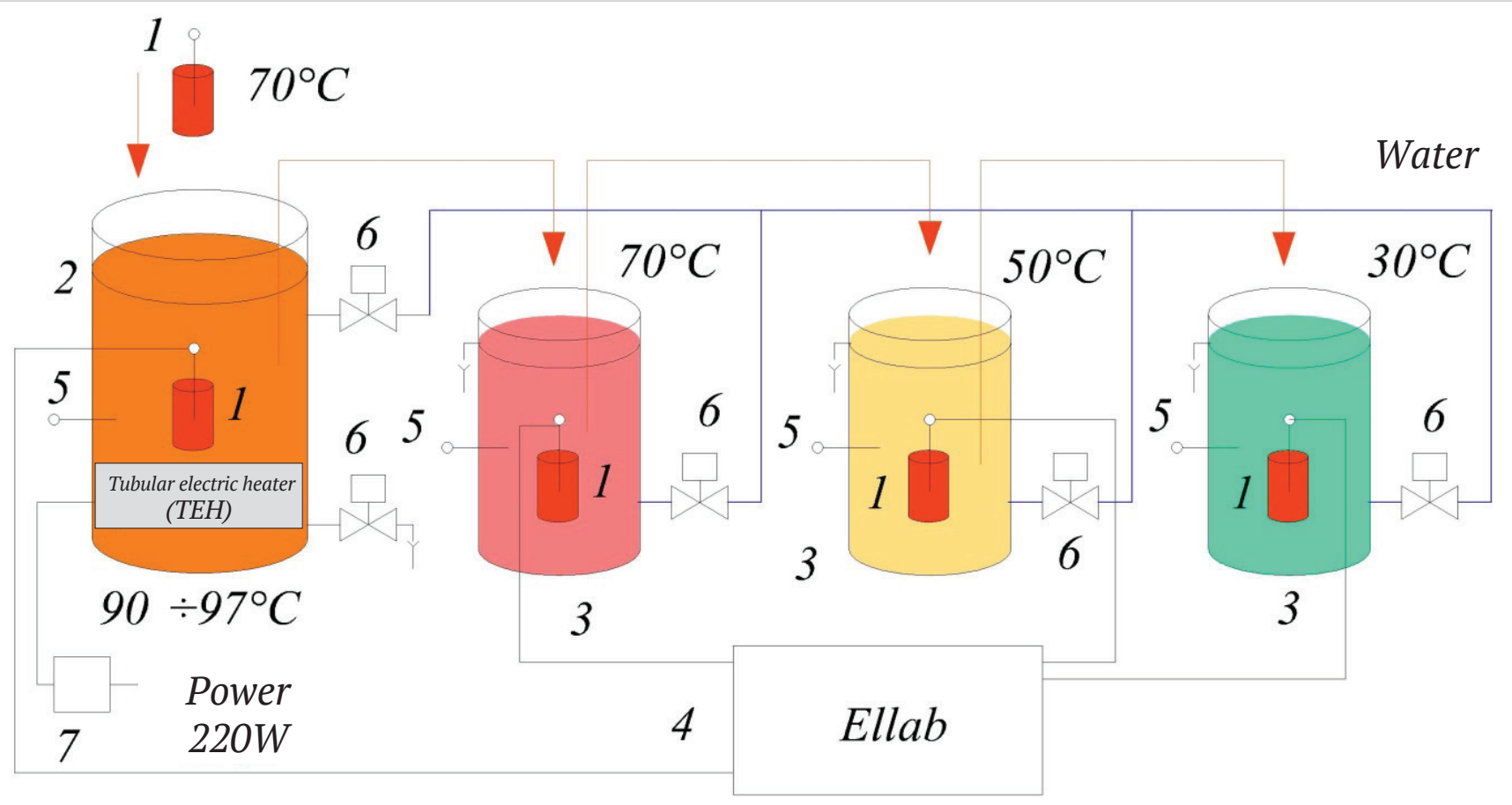

Figure 1. The scheme of the experimental stand, simulating the work of CAP

1 - can with thermocouple, 2 - autoclave, 3 - cooling section (thermostats), 4 - temperature recorder, 5 - temperature sensor, 6 - water valve, 7 - heating control unit 
The heating capacity of canned food during pasteurization depends mainly on its texture determined by the recipe, the size and material of the package, as well as the initial temperature of the product and the pasteurization temperature. The greatest efficiency of the pasteurization mode can be achieved by increasing the pasteurization temperature or the product packing temperature.

The rate of heat transfer in the jars with the product was determined by heating of the canned food in an open autoclave (which simulated the heating zone with water at a temperature of $97^{\circ} \mathrm{C}$, $95^{\circ} \mathrm{C}, 90^{\circ} \mathrm{C}$ ), and cooling in 3 tanks with water at a temperature of $70^{\circ} \mathrm{C}, 50^{\circ} \mathrm{C}$ and $30^{\circ} \mathrm{C}$ turn-by-turn (cooling zone of the pasteurizer). The temperature of the heating and cooling water as well as the temperature of the product, was measured by the thermocouples and «Ellab» potentiometer. The hot junction of the thermocouple was placed into the least heated area of the product. In high-sugar products heat transfer occurs only due to thermal conductivity, so the hot junction of the thermocouple was placed in the geometric center of the product packed in a glass jar [17].

The pasteurization modes were calculated basing on the fact that the about $1 / 3$ value of the actual lethality is achieved by the heat-conducting products during their heating up, and $2 / 3$ are achieved during cooling down.

According to the obtained experimental data on heating rate of the canned food calculated the value of the actual lethality. To calculate the lethality rate, the temperature in the product was read at regular intervals (every 5 minutes). The corresponding lethality coefficients for these product temperature readings were added and the resulting sum was multiplied by the accepted time interval and in this way the actual lethality value was obtained.

The lethality value is the value of lethality per 1 minute at a certain temperature in the least heated point of the product. The lethality value was calculated by the formula:

$$
l=10 \frac{T_{\text {product }}-T_{\text {bas }}}{z}
$$

where

$\mathrm{Z}-$ is the constant of thermal stability of the test-microorganism, ${ }^{\circ} \mathrm{C}$.

In this case $z=15^{\circ} \mathrm{C}$, and the base temperature $\left(T_{b a s}\right)$ is $80^{\circ} \mathrm{C}$.

During the tests on the stand, the marmalade was heated up to a packing temperature $70{ }^{\circ} \mathrm{C}$, which is $3-5^{\circ} \mathrm{C}$ below the temperature used in production conditions. In production conditions the packaged product immediately enters the pasteurizer almost

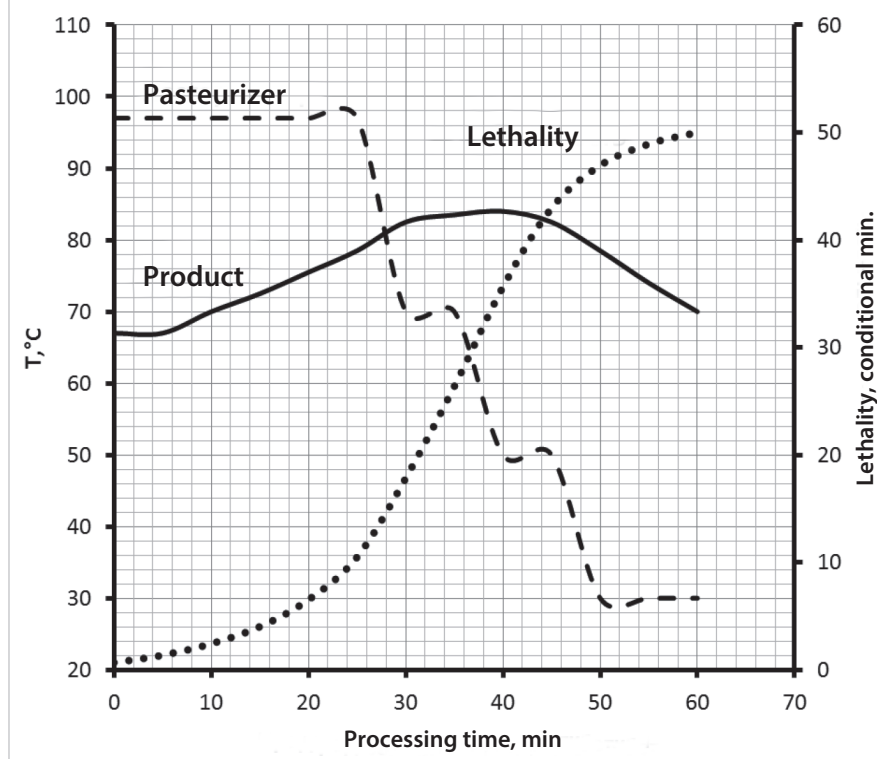

Figure 2. The chart of the temperature changes of the heating area in the autoclave (at $97^{\circ} \mathrm{C}$ ) and strawberry marmalade when heated in a glass jar 1 without cooling. This product is packed in 2 stages: first - the berries are packed in a jar, and then they are poured by syrup.

Pasteurization modes were developed for high-sugar products (marmalade), the packing temperature of which cannot be raised to the temperature of the pasteurization zone, according to the production technology.

Products with a low packing temperature $\left(70^{\circ} \mathrm{C}\right)$ must stay longer in the pasteurization zone. For other types of high-sugar canned food (jams, confitures and, berries pureed with sugar), which packing temperature can be raised higher, they will meet the requirements of industrial sterility even higher, if pasteurization is carried out according to the modes developed for marmalade.

According to the experimental data obtained at the stand, charts of temperature changes curve in the heating area and the temperature in the least heated point of the product with indication of the actual lethality value (Figure 2 and Figure 3 ) are constructed. The heating of canned food for recording of temperature change curves was carried out in three replications.

Below there are presented the data of processing of experimentally obtained heating curves and pasteurization modes of high-sugar cans for continuous-acting immersive pasteurizers at heating area temperatures $97^{\circ} \mathrm{C}, 95^{\circ} \mathrm{C}$ and $90^{\circ} \mathrm{C}$.

For high-sugar products (strawberry marmalade), packed in a glass jar 1 on the stand, was processed in the following modes of pasteurization with the calculation of the actual lethality:

$\frac{25 \mathrm{~min}}{97^{\circ} \mathrm{C}}-\frac{10 \mathrm{~min}}{70^{\circ} \mathrm{C}}-\frac{10 \mathrm{~min}}{50^{\circ} \mathrm{C}}-\frac{15 \mathrm{~min}}{30^{\circ} \mathrm{C}} A_{80}^{z=15}=50.01$ conditional min
$\frac{25 \mathrm{~min}}{95^{\circ} \mathrm{C}}-\frac{10 \mathrm{~min}}{70^{\circ} \mathrm{C}}-\frac{10 \mathrm{~min}}{50^{\circ} \mathrm{C}}-\frac{15 \mathrm{~min}}{30^{\circ} \mathrm{C}} A_{80}^{Z=15}=47.59$ conditional min
$\frac{30 \mathrm{~min}}{90^{\circ} \mathrm{C}}-\frac{10 \mathrm{~min}}{70^{\circ} \mathrm{C}}-\frac{10 \mathrm{~min}}{50^{\circ} \mathrm{C}}-\frac{15 \mathrm{~min}}{30^{\circ} \mathrm{C}} A_{80}^{Z=15}=47.41$ conditional min

The obtained values of the actual lethality were compared with the value of the required lethality $-A_{T=80^{\circ} \mathrm{C}}^{Z=10^{\circ} \mathrm{C}}=40 \div 80$. The choice of the optimal pasteurization mode is determined by the duration of the pasteurization process. For marmalade, packed in the glass jar 1, this mode was the following:

$\frac{25 \mathrm{~min}}{95^{\circ} \mathrm{C}}-\frac{10 \mathrm{~min}}{70^{\circ} \mathrm{C}}-\frac{10 \mathrm{~min}}{50^{\circ} \mathrm{C}}-\frac{15 \mathrm{~min}}{30^{\circ} \mathrm{C}}$ with the value of the actual lethality $A_{80}^{Z=15}=50.01$ conditional min

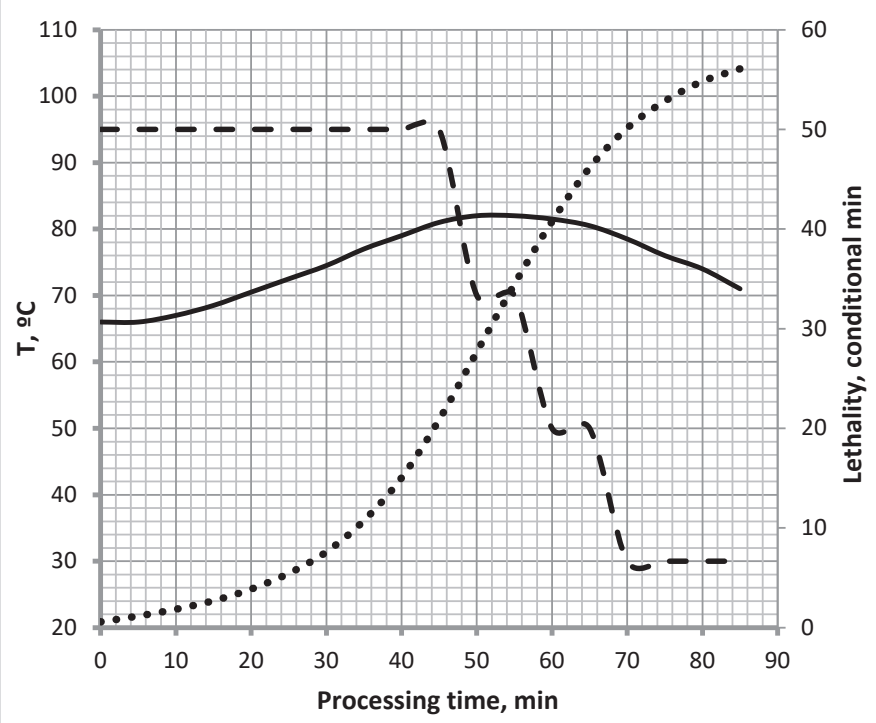

Figure 3. The chart of the temperature changes of the heating area in the autoclave (at $95^{\circ} \mathrm{C}$ ) and strawberry marmalade when heated in a glass jar 2 
For high-sugar products (strawberry marmalade), packed in a glass jar 2, the pasteurization modes are following:

$\frac{40 \mathrm{~min}}{97^{\circ} \mathrm{C}}-\frac{10 \mathrm{~min}}{70^{\circ} \mathrm{C}}-\frac{10 \mathrm{~min}}{50^{\circ} \mathrm{C}}-\frac{20 \mathrm{~min}}{30^{\circ} \mathrm{C}} \quad A_{80}^{z=15}=57.82$ conditional min.
$\frac{45 \mathrm{~min}}{95^{\circ} \mathrm{C}}-\frac{10 \mathrm{~min}}{70^{\circ} \mathrm{C}}-\frac{10 \mathrm{~min}}{50^{\circ} \mathrm{C}}-\frac{20 \mathrm{~min}}{30^{\circ} \mathrm{C}} \quad A_{80}^{z=15}=56.08$ conditional min
$\frac{50 \mathrm{~min}}{90^{\circ} \mathrm{C}}-\frac{10 \mathrm{~min}}{70^{\circ} \mathrm{C}}-\frac{10 \mathrm{~min}}{50^{\circ} \mathrm{C}}-\frac{20 \mathrm{~min}}{30^{\circ} \mathrm{C}} \quad A_{80}^{z=15}=48.71$ conditional min

The comparison of the obtained values of the actual lethality with the value of the required lethality $-A_{T=80^{\circ} \mathrm{C}}^{Z=15^{\circ}}=40 \div 80$ conditional $\mathrm{min}$, shows that the optimal pasteurization mode for marmalade, packed in a glass jar 2, was the following:

$\frac{40 \mathrm{~min}}{97^{\circ} \mathrm{C}}-\frac{10 \mathrm{~min}}{70^{\circ} \mathrm{C}}-\frac{10 \mathrm{~min}}{50^{\circ} \mathrm{C}}-\frac{20 \mathrm{~min}}{30^{\circ} \mathrm{C}}$ with the value of the actual lethality $A_{80}^{Z=15}=57.82$ conditional $\mathrm{min}$

So, for the established modes of pasteurization the optimal modes are: the heating (heat treatment) in an autoclave at a temperature of the heating area $97^{\circ} \mathrm{C}$ and step-by-step cooling of the product by water with temperature $70^{\circ} \mathrm{C}, 50^{\circ} \mathrm{C}$ and $30^{\circ} \mathrm{C}$. The time of food exposure in the heating zone is 25 minutes (for jar 1) and 40 minutes (for jar 2), in 1-st and 2-nd cooling zones the jars are exposed for 10 minutes, in the last cooling zone for the product, packaged in glass jar 1 is cooled for 15 minutes, and the product, packed into the glass jar 2 is cooled for 20 minutes.

The temperature of the product conveyed to the CAP pasteurization zone, must not be lower than $70^{\circ} \mathrm{C}$. Increasing the product packing temperature on $5^{\circ} \mathrm{C}$ will reduce the pasteurization mode, and that will reduce the time of exposure in the heating zone for 7-10 minutes.

The canned food, produced according to the obtained pasteurization modes, meet the requirements of industrial sterility. When determining the compliance of canned food with the requirements of industrial sterility, the absence of mold fungi (including Penicillium glaucum) and yeast was confirmed by plating of DG 18 with dichlorane and glycerin into agarized nutrient medium.

It is necessary to take into account the characteristics of the equipment available at the enterprises in order to optimize the pasteurization modes, then to produce experimental batches of canned food, put them for 3-month storage, further open the can and conduct microbiological studies in accordance with the requirements of industrial sterility.

\section{Conclusion}

Upon the results of the work:

1. There have been developed the optimal pasteurization modes of high-sugar canned food for continuous-acting pasteurizers of immersive type with the temperature of the heating area below $100{ }^{\circ} \mathrm{C}$ and for various types of jars.

2. The developed modes of pasteurization of high-sugar canned food can be recommended for continuous-acting pasteurizers of irrigational type. In this case, preference should be given to pasteurizers with a temperature in the heating zone not less than $95^{\circ} \mathrm{C}$.

3. For achieve the industrial sterility of high-sugar cans and to reduce the duration of the pasteurization process, it is necessary:

- to ensure the product packing temperature from $70^{\circ} \mathrm{C}$ and higher till to the maximum permissible values $\left(85-90^{\circ} \mathrm{C}\right)$;

- to ensure minimum distance between the capping machine and the entry of the product to the pasteurizer in order to minimize the loss of product temperature in the package;

- to provide automatic maintenance of the set temperatures on zones of heat treatment (pasteurization) and cooling.

4. Continuous-acting pasteurizers can be recommended for the production of other types of high-sugar and high-acid canned food: marmalade, jams, concentrated juices and tomato products, etc.

\section{REFERENCES}

1. 1. Marszałek, K., Woźniak, Ł., Skąpska, S., Mitek, M. (2017). High pressure processing and thermal pasteurization of strawberry purée: quality parameters and shelf life evaluation during cold storage. Journal of Food Science and Technology, 54(3), 832-841. DOI: 10.1007/s13197-017-2529-4

2. Peng, J., Tang, J., Barrett, D.M., Sablani, S.S., Anderson, N., Powers, J.R. (2017). Thermal pasteurization of ready-to-eat foods and vegetables: Critical factors for process design and effects on quality. Critical Reviews in Food Science and Nutrition, 57(14), 2970-2995. DOI: 10.1080/10408398.2015.1082126

3. Rolfey, E.J., M. Caryl, Robson, L.G. et al. (1980). Food products with intermediate moisture. Moscow: Food industry. -208 p.

4. Silva, F.V.M., Gibbs, P.A. (2009). Principles of thermal processing: pasteurization. Chapter 2 in book: Engineering Aspects of Thermal Food Processing. CRC Press, Taylor and Francis Group, Boca Raton, USA. ISBN: 978-1-4200-5858-1

5. Kondratenko, V.V., Levshenko, M.T., Petrov, A.N, Pozdnyakova, T.A., Trishkaneva, M.V. (2019). Comparative evaluation of approaches to modelling kinetics of microbial thermal death as in the case of Alicyclobacillus acidoterrestris. Foods and Raw Materials, 7(2), 348-363. DOI: 10.21603/2308-4057-2019-2-348-363

6. Babarin, V.P. (2006). Handbook of sterilization of canned food. St-Peterburg: Giord, -306 p. ISBN: 5-98879-039-9

7. Evelyn, Silva, F. V. M. (2018). Differences in the resistance of microbial spores to thermosonication, high pressure thermal processing and thermal treatment alone. Journal of Food Engineering, 222, 292-297. DOI: 10.1016/j.jfoodeng.2017.11.037

8. Levshenko, M.T., Kanevsky, B.L. (2018). Calculation optimization of microorganisms required letality at the sterilization and pasterization modes development of homogeneous fruit preserves. Collection of scientific papers "Actual problems of the beverage industry», 2, 81-86. DOI: $10.21323 / 978-5-6041190-3-7-2018-2-81-86$
9. Pereira, R., Martins, J., Mateus, C., Teixeira, J., Vicente, A. (2007). Death kinetics of Escherichia coli in goat milk and Bacillus licheniformis in cloudberry jam treated by ohmic heating. Chemical Papers, 61(2). DOI:10.2478/s11696-007-0008-5

10. Setlow, P., Johnson, E. (2019). Spores and Their Significance, p. 23-63. In Doyle M, Diez-Gonzalez F, Hill C (ed), Food Microbiology: Fundamentals and Frontiers, 5th Edition. ASM Press, Washington, DC. DOI: 10.1128/9781555819972.ch2

11. Worobo, R. W., Splittstoesser, D. F.(2004). Microbiology of fruit products, p. 161-284. In D. M. Barret, L. Somogyi, H. Ramaswamy (Eds.), Processing fruit 2005, 2nd ed., pp. 161-284. Boca Raton: CRC Press, Taylor and Francis Group. DOI: 10.1201/9781420040074.ch12

12. Lewis, M. (2010). Engineering Aspects of Thermal Food Processing. International Journal of Dairy Technology, 2010, 63(4), 601-602. doi:10.1111/j. 1471 0307.2010.00592.x

13. Maslov, A.M. (1980). Devices for heat treatment of highly viscous liquids. Leningrad: Mashinostroenie. - 206 p.

14. Aminov, M.S., Muradov, M.S., Aminova, E.M. (1999). Processes and devices of food production. Moscow: Kolos. $-504 \mathrm{p}$.

15. Gut, J.A.W., Pinto, J.M. (2003). Selecting Optimal Configurations for Multisection Plate Heat Exchangers in Pasteurization Processes. Industrial and Engineering Chemistry Research, 42(24), 6112-6124 doi:10.1021/ ie0303810

16. Kiziltaş, S., Erdoğdu, F., Koray Palazoğlu, T. (2010). Simulation of heat transfer for solid-liquid food mixtures in cans and model validation under pasteurization conditions. Journal of Food Engineering, 97(4), 449456. DOI: 10.1016/j.jfoodeng.2009.10.042

17. Derossi, A., De Pilli, T., La Penna, M.P., Severini, C. (2012). Prediction of heating length to obtain a definite $F$ value during pasteurization of canned food. Journal of Food Process Engineering, 36(2), 211-219. doi:10.1111/j.1745-4530.2012.00674.x 


\section{INFORMATION ON THE AUTHORS}

Galina P. Pokudina - senior Researcher, Laboratory of canning production processes and equipment, Russian Research Institute of Canning Technology Branch of V. M. Gorbatov Federal Research Center for Food Systems of RAS, 142703, Moscow region, Vidnoye, School str, 78, Tel.: +7-495-668-70-31 e-mail: konservtech@rambler.ru.

*corresponding author

Marina V. Trishkaneva - candidate of chemical sciences, leading researcher, Laboratory of scientific and technical analysis, Russian Research Institute of Canning Technology - Branch of V. M. Gorbatov Federal Research Center for Food Systems of RAS, 142703, Moscow region, Vidnoye, School str, 78, +7-495548-51-22, e-mail: labnta@vniitek.ru

Raisa A. Volkova - leading research scientist, Laboratory of quality and food safety, Russian Research Institute of Canning Technology - Branch of V. M. Gorbatov Federal Research Center for Food Systems of RAS, 142703, Moscow region, Vidnoye, School str, 78, +7-495-668-70-37, e-mail: raj volkova@mail.ru.

All authors bear responsibility for the work and presented data.

All authors made an equal contribution to the work.

The authors were equally involved in writing the manuscript and bear the equal responsibility for plagiarism.

The authors declare no conflict of interest.

Received 02.08.2019 Accepted in revised 25.11.2019 Accepted for publication on 16.12.2019 